\title{
Minimally Invasive Non-Endoscopic Correction for Sagittal Craniosynostosis in Children Aged Below 6 Months
}

\author{
Khaled Bassim, Ayman Farghal* ${ }^{*}$ Amr Mostafa Elkatatny \\ Neurosurgery Children Unit, Cairo University, Abu El Reesh Japanese Hospital, Cairo, Egypt
}

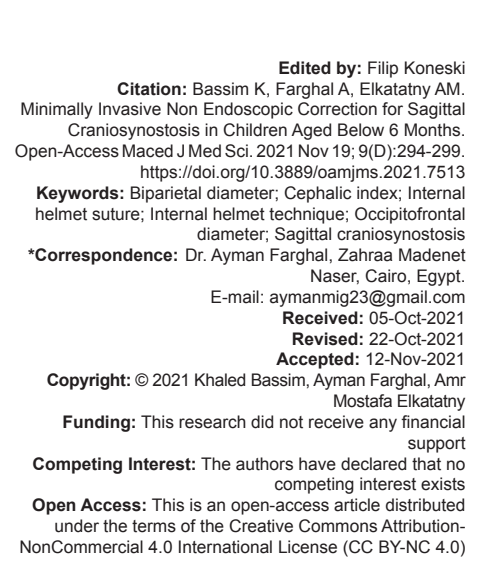

Abstract

AIM: Object of this study is to determine effectiveness of this procedure used in this study which is minimally invasive non endoscopic correction for sagittal craniosynostosis in children below 6 months.

METHODS: A prospective study was done in Neurosurgery children unit, Abu Elreash Japanese children hospital, Cairo university, Egypt, for patients with non syndromatic sagittal craniosynostosis. The variables analyzed; OFD, $\mathrm{BPD}, \mathrm{Cl}$ pre. \& postoperative, age of patients at time of surgery, sex, duration of surgery and length of hospital stay. RESULTS: Our results shows statistically significant difference between pre-operative with post-operative after 2 days, post-operative follow-up, and follow-up after 1 year for OFD, BPD and Cl.

CONCLUSIONS: Internal helmet technique used in correction of sagittal synostosis in children below 6 months old giving good cosmetic results with the following advantages, (1) short surgery time, (2) small wound, (3) no much blood loss, (4) immediate good cosmetic result, (5) no need to use external devices which reduces the cost, family load, and child suffering, and (6) no need for long-term follow-up.

\section{Introduction}

Sagittal synostosis is the most prevalent type of craniosynostosis with an incidence of 1 in 4200 births [1]. Premature closure of the sagittal suture is associated with the poor esthetics of an elongated head shape with frontal and occipital bossing, and has been associated with increased intracranial pressure [2], disruption in blood flow [3], and poor neurologic development. Early treatment of synostosis allows for correction of cosmetic deformities and may have a positive impact on neurological development. The earliest surgical techniques described for the treatment of sagittal synostosis involved removal of fused suture and were performed by Lannelongue [4] followed by Lane in the 1890s. These early approaches, focused on removing the suture, had a high level of failure [5], and soon gave way to more extensive cranial vault remodeling CVR techniques, but there was a rise of massive intraoperative blood loss and long duration of surgery as in open technique, sometimes unacceptable results, and use of post-operative helmet which is irritating to child and parents and costly with longterm follow-up, also spring mediated cranioplasty and external distractor use which have the problems of external device coming out of child's head.
Then, minimally invasive techniques have been used with and without endoscope giving variable cosmetic results and some improvement in both frontal and occipital bossing, with different degrees of recurrence.

\section{Methods}

\section{Patient variables}

A prospective study done in Neurosurgery children unit, Abu El Reesh Japanese Children hospital, Cairo University, conducted on 30 patients from 2018 to 2020 all are surgically operated by professor Dr. Khaled Bassim with his assistant Dr. Ayman Farghal using minimally invasive technique, patients clinical assessment was done with comparing the following variables; occipitofrontal diameter (OFD), biparietal diameter (BPD), cephalic index (Cl), hemoglobin (HGB), and both pre-operative and post-operative, other variables include patients age at surgery, sex, and duration of surgery. Patients followed after surgery for 12 months and 18 cases followed for periods up to 17 months. 


\section{Surgical techniques}

Following induction of general anesthesia, orotracheal intubation was performed with use of supine semi-setting position. A pre-operative $2^{\text {nd }}$ generation cephalosporin given IV $1 \mathrm{~h}$ before surgery. 3-4 cm skin incision centered over middle one-third of sagittal suture (Figures 1 and 2a), removal of middle one-third of sagittal suture (by applying burr hole then expanding), dissecting dural all over, especially at coronal and lambdoid sutures (important step to prevent dural tear and it's complication), radial cuts were done on both sides of parietal bone anteriorly crossing coronal suture, and also posteriorly on both sides of the parietal bone Figure $2 b$ (four blue arrows). Then, a piece meal removal of middle one-third of parietal bones bilaterally. Then, using a drill to make four holes in parietal bones anteriorly and posteriorly in a fashion seen in Figure 2b (4 red arrows) then applying double silk suture size 1 on the right side and also double in the left side to approximate parietal bone in fronto-occipital direction (this approximation is done by assistant; applying one hand palm on the forehead and the other palm on the occipital region then gentle gradual approximation is done and the surgeon start to apply sutures) (Figures 1 and 2).

- There is immediate reduction of OFD postoperatively (Figure 2c).

$\mathrm{CT}$ brain bone window with $3 \mathrm{D}$ reconstruction was done 2 days post-operative and also at variable periods of follow-up, up to 17 months post-operative for comparing OFD, BPD, and $\mathrm{Cl}$ (Figures 4-6).

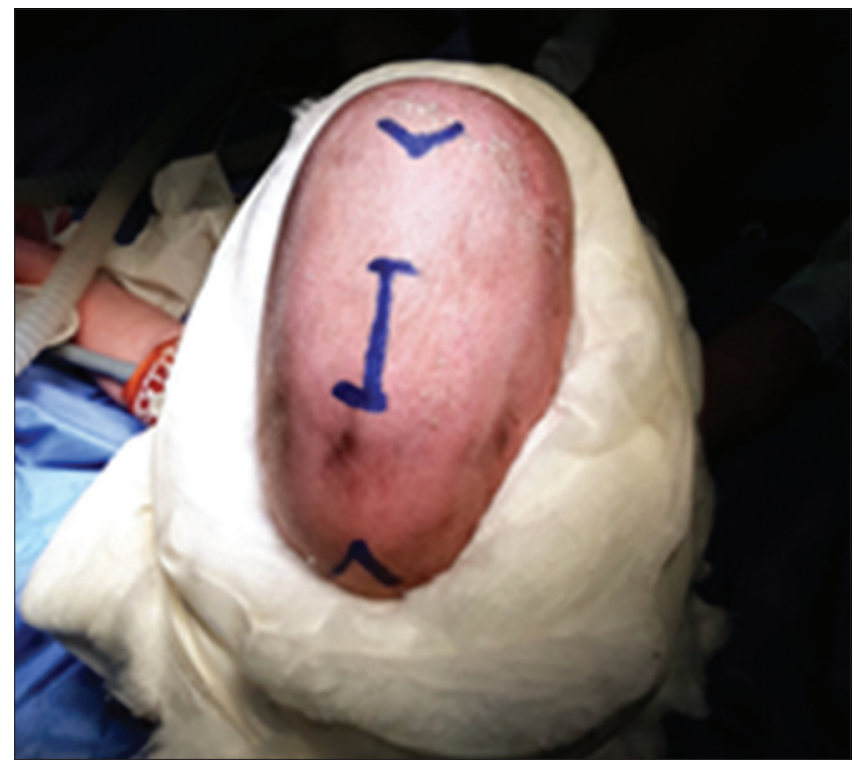

Figure 1: Skin incision mark which is centered over middle one-third of sagittal suture and identification of both anterior and posterior fontanel. Also note large OFD with prominent fused sagittal ridge and head support with cotton band

\section{Results}

\section{Statistical analysis}

Recorded data were analyzed using the Statistical Package for the Social Sciences, version 20.0 (SPSS Inc., Chicago, Illinois, USA). Quantitative data were expressed as mean \pm standard deviation (SD). Qualitative data were expressed as frequency and percentage.

\section{The following tests were done}

- $\quad$ Paired sample t-test of significance was used when comparing between related samples.

- $\quad$ The confidence interval was set to $95 \%$ and the margin of error accepted was set to $5 \%$. Hence, the $p$ value was considered significant as the following

- $\quad$ Probability ( $p$-value)

- $\quad p<0.05$ was considered significant.

- $\quad \mathrm{p}<0.001$ was considered as highly significant.

- $\quad p>0.05$ was considered insignificant.

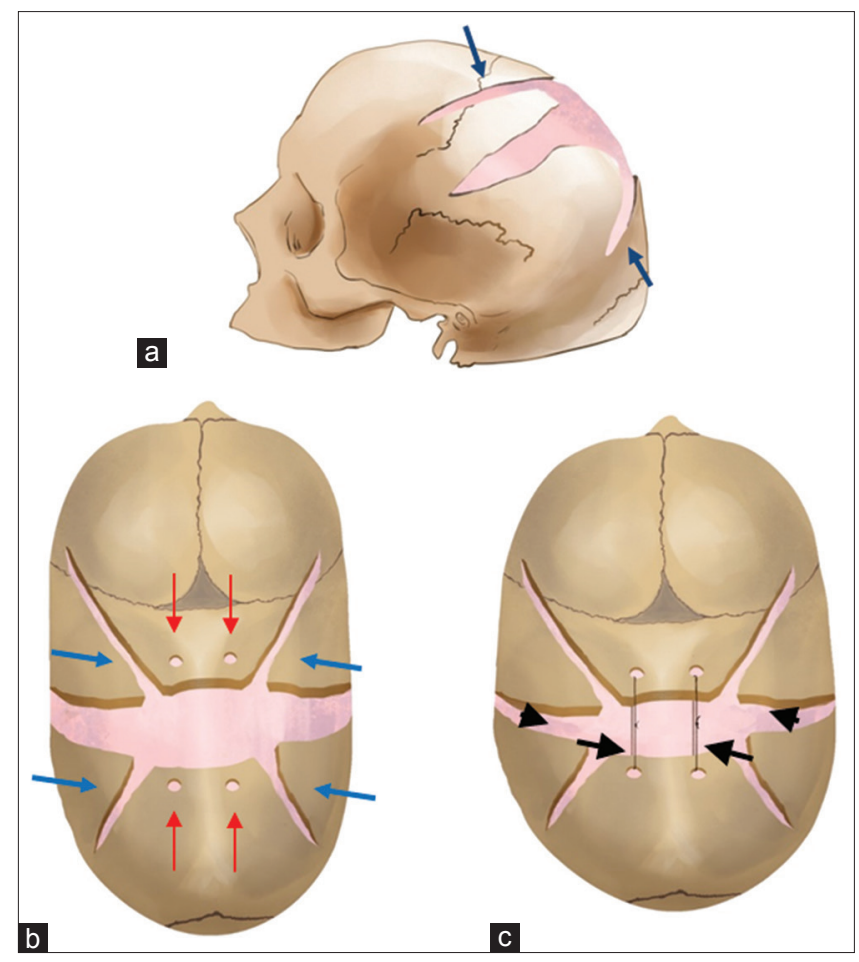

Figure 2: (a) Lateral view showing radial cuts in parietal bone anteriorly crossing coronal suture and posteriorly (blue arrows). (b) Top view showing removed middle one-third of sagittal suture, removed middle part of parietal bone on the right and left side (arrows head) and radial cut in parietal bone anteriorly which cross coronalsutural and also posteriorly (blue arrows), in addition to holes done by drill anteriorly and posteriorly in parietal bone the right and left to sagittal suture (red arrows). (c) Top view showing application of silk suture right and left to sagittal suture to make approximation in fronto-occipital direction (black arrows). Note shorting of the skull and relative widening of biparietal diameter after suture application 
The results of the present study are demonstrated in the following Tables 1-4 and figures.

This table shows that the female percentage is $23.3 \%$ and male percentage is $76.7 \%$ of sex, also mean age is $4.11 \pm 0.92$, while mean of operation time is $48.00 \pm$ 5.00 and mean post-operative hospital stay is $3.53 \pm 6.22$.

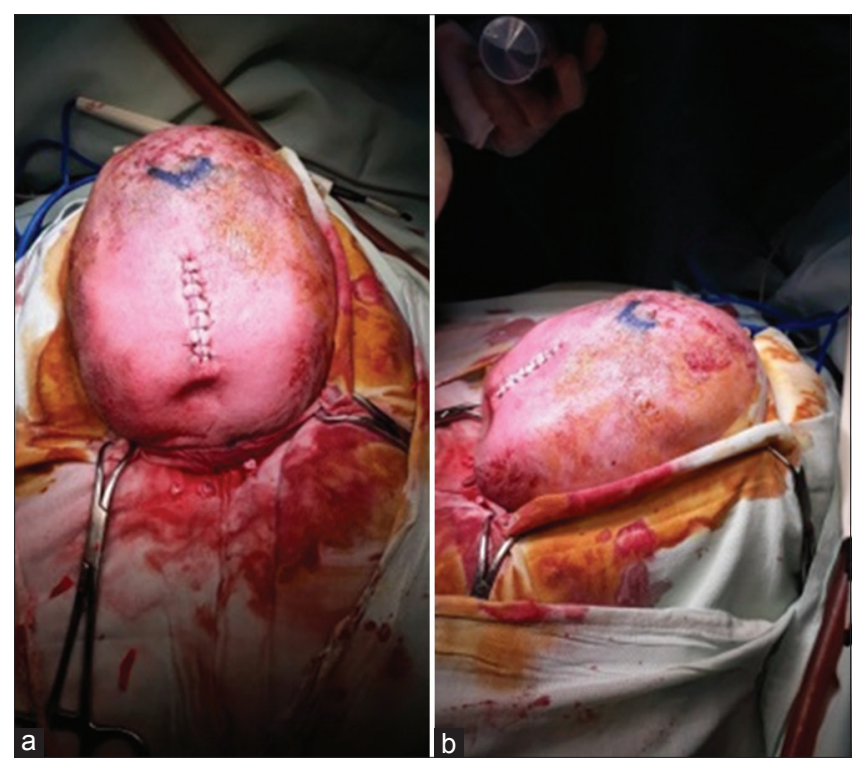

Figure 3: (a and b) Post-operative top and lateral views, respectively Note reduction of occipitofrontal diameter and widening of biparietal diameter

Table 2 shows statistically significant difference between pre-operative with post-operative after 2 days, post-operative follow-up, and follow-up after 1 year for OFD.

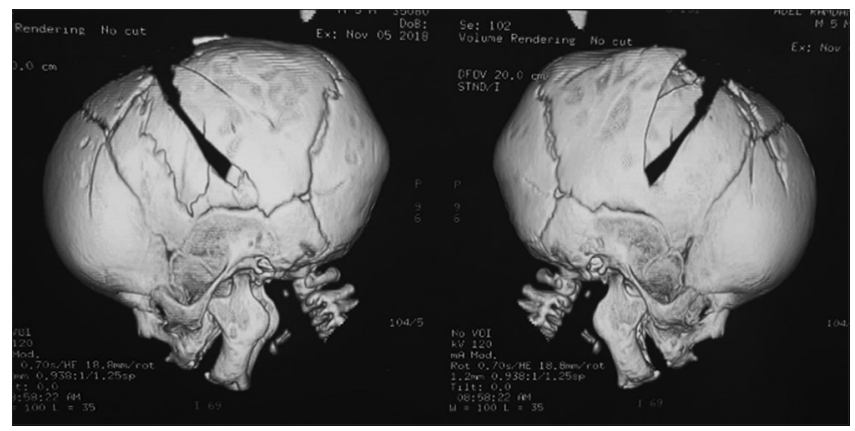

Figure 4: $R T$ and $L T$. $2^{\text {nd }}$ day post-operative $3 D$ reconstruction $C T$ skull showing middle piece meal excision of both RT and LT. Parietal bone using wire cutter scissor

Table 3 shows statistically significant difference between pre-operative with post-operative after 2 days, post-operative follow-up, and follow-up after 1 year for BPD.

Table 4 shows statistically significant difference between pre-operative with post-operative after 2 days, post-operative follow-up, and follow-up after 1 year for $\mathrm{Cl}$.

There is male predominance in this study $76.7 \%$ (23 cases) and female percentage was $23.3 \%$ (seven cases).

Mean age of patients 4.1 months ranging from 2.7 to 5.7 , age limit not exceeding 6 months because

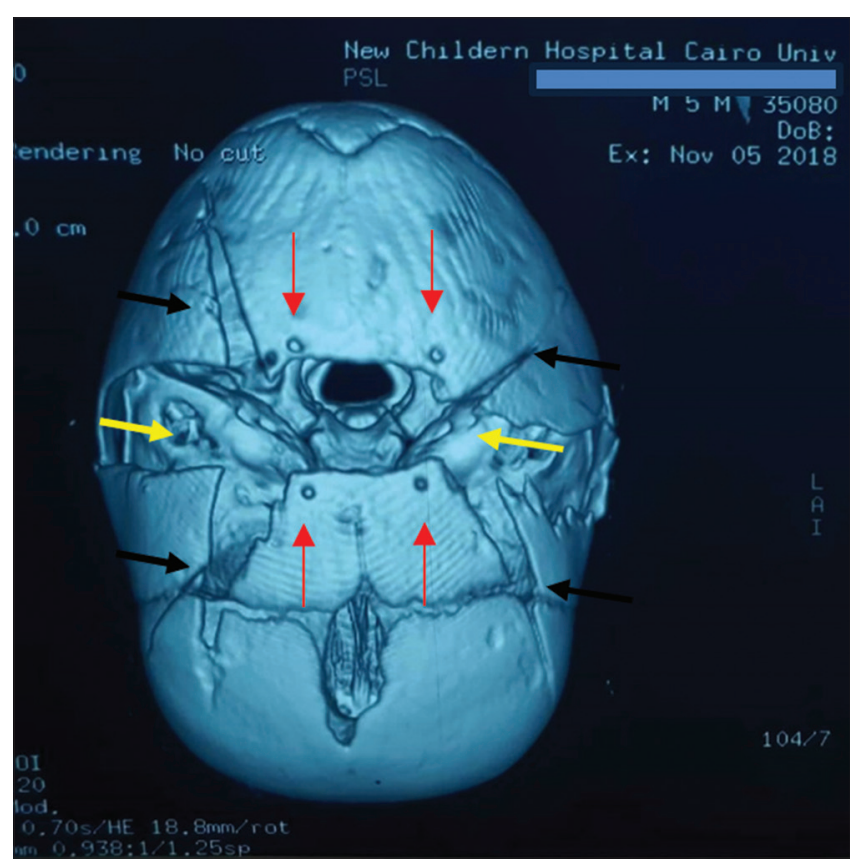

Figure 5: Top view $2^{\text {nd }}$ day post-operative $3 D$ reconstruction $C T$ skull with excision of middle one-third of sagittal suture, middle piece meal excision of both RT and LT. Parietal bones (yellow arrows) and radial cut of both parietal bone anterior and posterior (black arrows), using wire cutter scissor. Note also holes done by drill on both sides of parietal bone near sagittal suture anterior and posterior (red arrows)

this technique used thought to be not suitable above 6 months due to increased bone thickness which

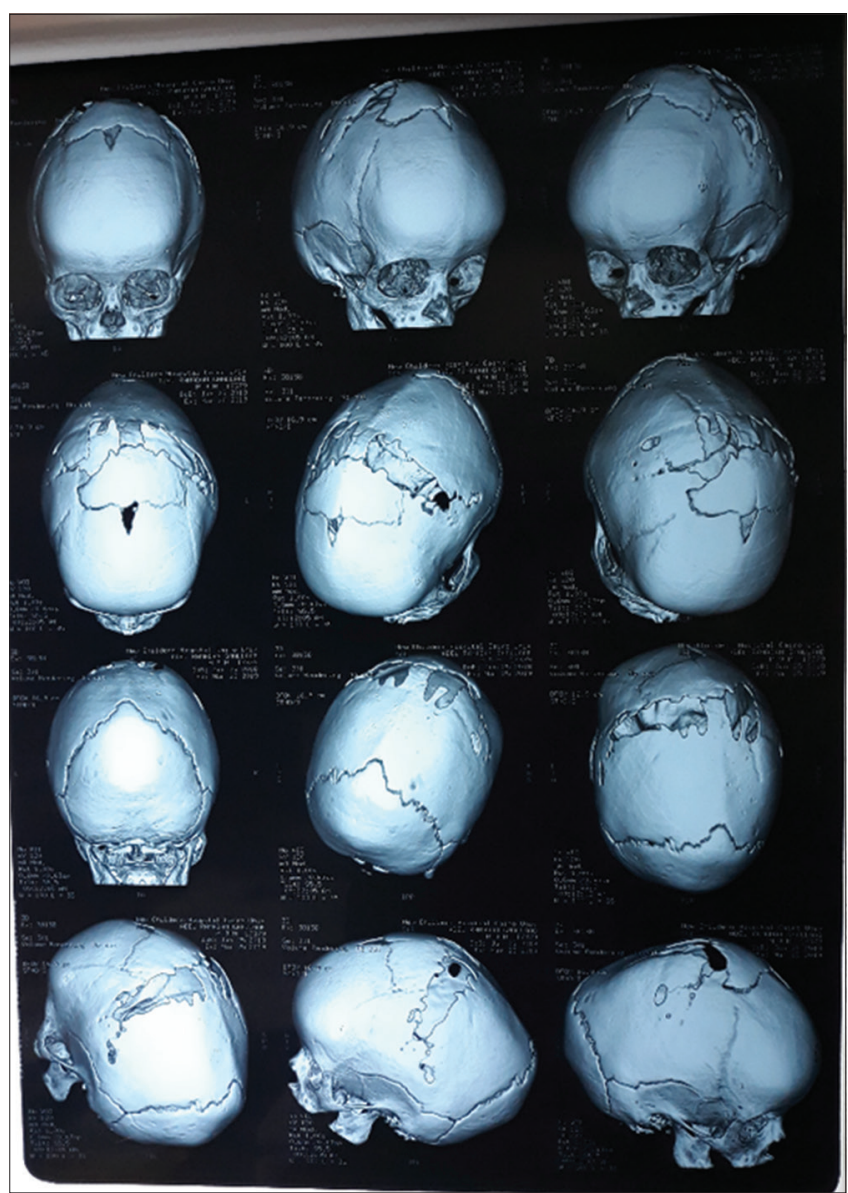

Figure 6: Post-operative CT skull 3D reconstruction after 4 months follow-up 
requiring more calvarial bone remodeling. Mean operation time (started from skin incision to end of wound closure) 48 min ranging from 35 to $57 \mathrm{~min}$. Mean post-operative hospital stay 3.53 ranging from 2 to 35 days, 25 cases of total 30 cases discharged after 2 days, and three cases discharged after 3 days.
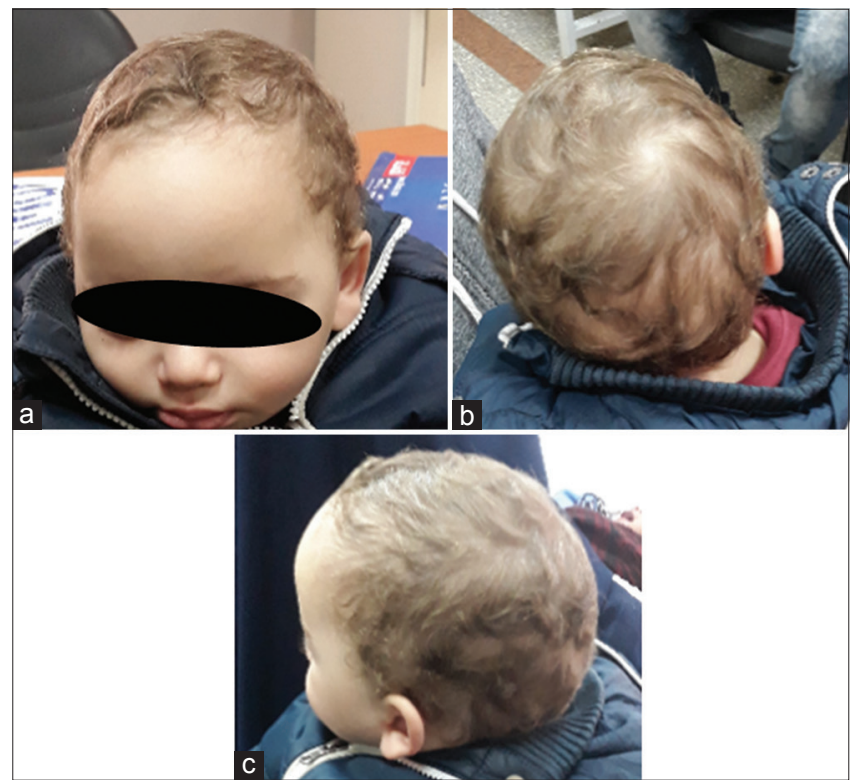

Figure 7: (a) Postoperative front view for child who underwent minimally invasive nonendoscopic sagittal synostosis corection 4 months after surgery shows some improvement in frontal bossing. (b) Postoperative back view shows restoring of normal $\mathrm{Cl}$, adequate skull shape, good cosmotic results in reduced AP diameter, widing of BPD.(c) Postoperative side view shows improved occipital bossing.

\section{Discussion}

In our study, results showing reduction in OFD immediately post-operative with mean \pm SD of

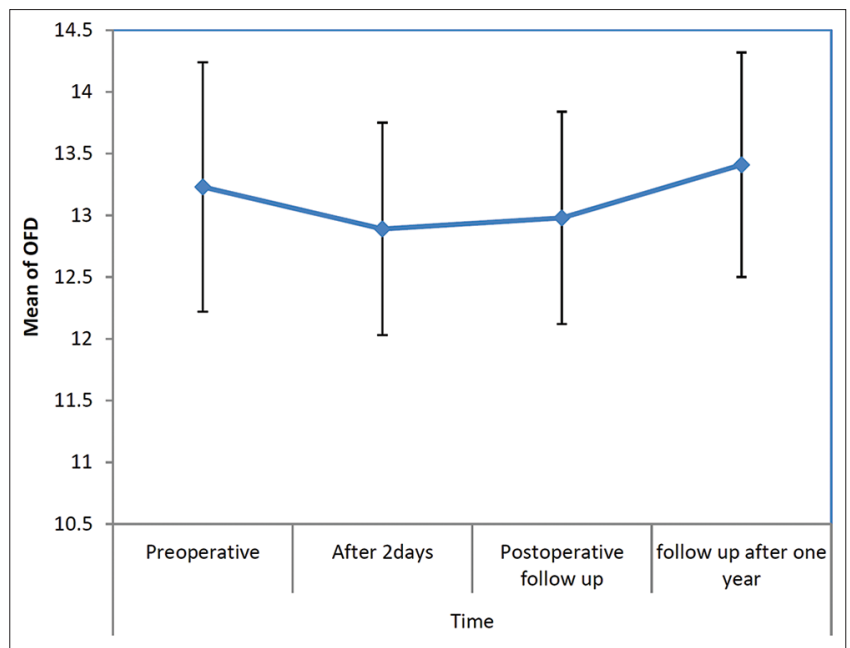

Figure 8: Line shows the extent of the difference over the periods through occipitofrontal diameter in the study group pre-operative OFD of $13.23 \pm 1.01$, post-operative mean \pm SD of OFD after 2 days $12.89 \pm 0.86$, $p$-value is highly significant of $<0.001$, OFD follow-up in periods ranging from 45 to 150 days (mean \pm SD $107.24 \pm 28.24$ ) is $12.98 \pm 0.86, p$-value is highly significant of $<0.001$, and OFD follow-up after 1 year in periods ranging from 12 to 17 months (mean \pm SD $14.52 \pm 2.76$ ) is $13.41 \pm 0.91$ (Figures 7 and 8).

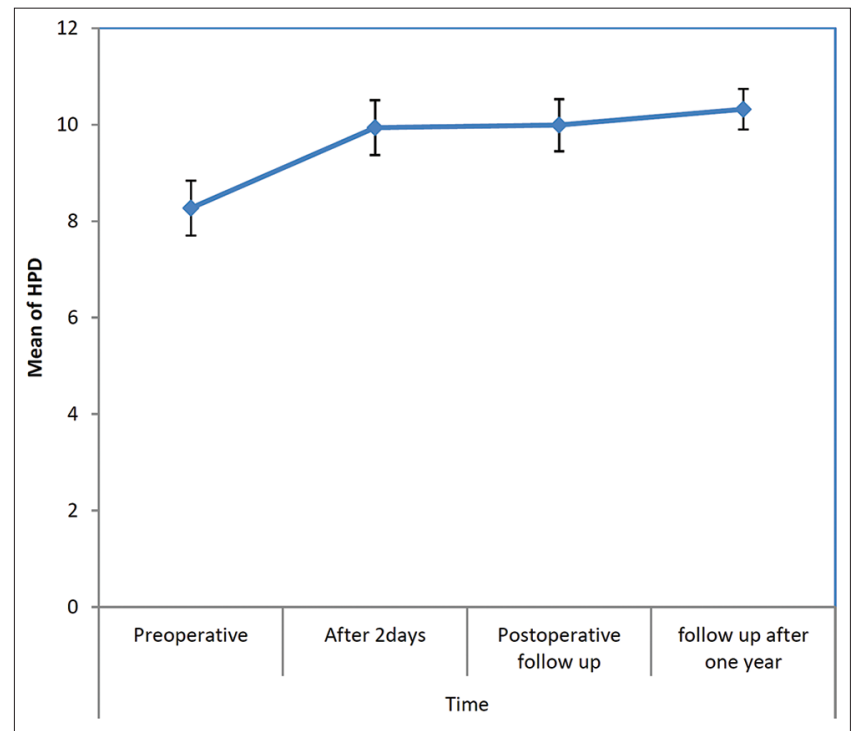

Figure 9: Line shows the extent of the difference over the periods through biparietal diameter in the study group

Furthermore, there is increase in BPD immediately post-operative with mean \pm SD of pre-operative BPD $8.27 \pm 0.57$, post-operative mean \pm $\mathrm{SD}$ of BP after 2 days $9.94 \pm 0.57$, p-value is highly significant of $<0.001$, Mean \pm SD BPD follow-up in periods ranging from 45 to 150 days (mean \pm SD $107.24 \pm 28.24)$ is $9.99 \pm 0.54, p$-value is highly significant of $<0.001$, and BPD follow-up after 1 year in periods ranging from 12 to 17 months (mean \pm SD $14.52 \pm 2.76$ ) is $10.32 \pm 0.42$ (Figure 9).

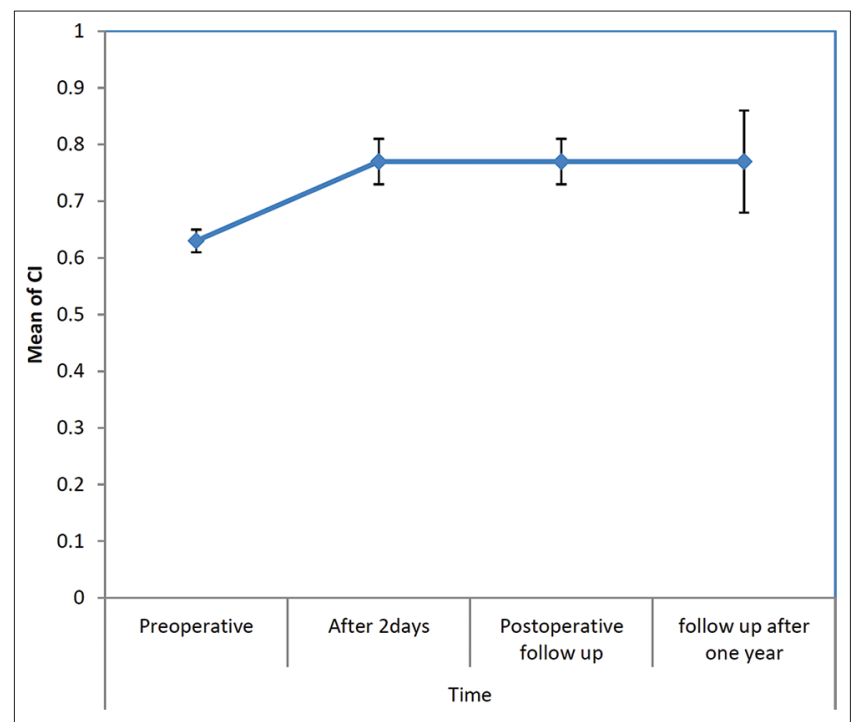

Figure 10: Line shows the extent of the difference over the periods through cephalic index in the study group 
Table 1: Baseline characteristics distribution of the study group

\begin{tabular}{ll}
\hline Baseline characteristics & Total $(\mathrm{n}=30)$ \\
\hline Sex & $7(23.3 \%)$ \\
$\quad$ Female & $23(76.7 \%)$ \\
$\quad$ Male & \\
Age (years) & $2.7-5.7(4.11 \pm 0.92)$ \\
$\quad$ Range $($ Mean \pm SD) & \\
Operation time (min) & $35-57(48.00 \pm 5.00)$ \\
$\quad$ Range (Mean \pm SD) & \\
Post-operative hospital stay & $2-35(3.53 \pm 6.22)$ \\
$\quad$ Range (Mean \pm SD) &
\end{tabular}

ard deviation.

Table 2: The extent of the difference over the periods through OFD in the study group

\begin{tabular}{llllll}
\hline OFD & Range & Mean \pm SD & Mean diff. & Paired t-test & p-value \\
\hline Pre-operative & $11-14.6$ & $13.23 \pm 1.01$ & & & \\
Post-operative after & $11.1-14$ & $12.89 \pm 0.86$ & -0.34 & 4.851 & $<0.001^{* *}$ \\
2 days & & & & & \\
Post-operative follow-up & $11.3-14.4$ & $12.98 \pm 0.86$ & -0.25 & 5.674 & $<0.001^{* *}$ \\
Follow-up after 1 year & $11.6-14.7$ & $13.41 \pm 0.91$ & 0.18 & 2.196 & $0.032^{*}$ \\
\hline${ }^{*, *}$ p $<0.001$ HS, SD: Standard deviation, OFD: Occipitofrontal diameter. & &
\end{tabular}

There is increase in $\mathrm{Cl}$ immediately post-operative with mean $\pm \mathrm{SD}$ of pre-operative $\mathrm{Cl} 0.63 \pm 0.02$, post-operative $\mathrm{Cl}$ after 2 days $0.77 \pm 0.04$, $\mathrm{p}$-value is highly significant of $<0.001$, and $\mathrm{Cl}$ follow-up in periods ranging from 45 to 150 days (mean \pm SD $107.24 \pm 28.24)$ is $0.77 \pm 0.04, p$-value is highly significant of $<0.001$, and OFD follow-up after 1 year in periods ranging from 12 to 17 months (mean \pm SD $14.52 \pm 2.76$ ) is $0.77 \pm 0.09$, in which you notice that $\mathrm{Cl}$ remains same in follow-up which reflects that cosmesis is still acceptable (Figure 10).

Table 3: The extent of the difference over the periods through BPD in the study group.

\begin{tabular}{llllll}
\hline BPD & Range & Mean \pm SD & Mean diff. & Paired t-test & p-value \\
\hline Pre-operative & $7-9.2$ & $8.27 \pm 0.57$ & & & \\
Post-operative after 2 days & $8.9-11$ & $9.94 \pm 0.57$ & 1.67 & -22.517 & $<0.001^{* *}$ \\
Post-operative follow-up & $9-11.1$ & $9.99 \pm 0.54$ & 1.72 & -21.934 & $<0.001^{* *}$ \\
Follow-up after 1 year & $9.4-11.5$ & $10.32 \pm 0.42$ & 2.05 & 24.683 & $<0.001^{* *}$ \\
\hline${ }^{* *}<0.001$ HS, SD: Standard deviation, BPD: Biparietal diameter. & & &
\end{tabular}

Although there is decline in eight cases in post-operative $\mathrm{Cl}$ follow-up compared to immediate post-operative $\mathrm{Cl}$ and four cases showed same $\mathrm{Cl}$ both pre- and post-operative, still there is improvement of the other cases observed in $\mathrm{Cl}$ and clinically.

Table 4: The extent of the difference over the periods through $\mathrm{Cl}$ in the study group

\begin{tabular}{llllll}
\hline $\mathrm{Cl}$ & Range & Mean \pm SD & Mean diff. & Paired t-test & $\mathrm{p}$-value \\
\hline Pre-operative & $0.57-0.68$ & $0.63 \pm 0.02$ & & & \\
Post-operative after 2 days & $0.70-0.86$ & $0.77 \pm 0.04$ & 0.14 & -21.570 & $<0.001^{* *}$ \\
Post-operative follow up & $0.69-0.83$ & $0.77 \pm 0.04$ & 0.14 & -20.884 & $<0.001^{* *}$ \\
Follow-up after 1 year & $0.69-0.82$ & $0.77 \pm 0.09$ & 0.14 & -14.713 & $<0.001^{* *}$ \\
\hline${ }^{*} \mathrm{p}<0.001 \mathrm{HS}, \mathrm{SD}:$ Standard deviation, Cl: Cephalic index. & & &
\end{tabular}

Three cases showed repeated vomiting postoperatively up to 4 times then in the $2^{\text {nd }}$ postoperative day vomiting stopped which is explained by partial elevation of ICP clinically and is thought to be caused by effect of shorting AP diameter.

The effect from shorting the skull by the approximation sutures (internal helmet sutures) on ICP and the possible potential rise of ICP thought to be neutralized by removed middle parts of the parietal bone on both sides, and simply, we can say that the decreased AP diameter effect on ICP is thought to be compensated by simultaneous increase in BPD, in which the room (skull cavity) for the brain is almost still same.

Furthermore, there is no much blood loss in these minimally invasive techniques with Mean \pm SD of pre-operative HGB $12.38 \pm 0.33 \mathrm{mg} / \mathrm{dl}$ and mean $\pm \mathrm{SD}$ of post-operative HGB $10.78 \pm 0.85 \mathrm{mg} / \mathrm{dl}$.

One case showed post-operative hemodynamic instability then stabilization reached and patient improved and discharged after 12 days from surgery and one case developed fever and upper respiratory tract symptoms after surgery then acquired chest infection and died after 35 days from surgery and it's follow-up CT brain was satisfactory.

Regarding the frontal bossing around 19 cases showed post-operative improvement with acceptable cosmesis, five cases show partial improvement and six cases remained the same pre- and post-operative, while occipital bossing improved in 24 cases and shows partial improvement in 6 cases.

It is not seems that approximation suture to cause sutural diastasis at coronal or lambdoid sutures as observed in follow-up.

Furthermore, it is noticed all over the study there are no wound complications such as infection or gaping though to be due to relatively small wound utilized in the technique encountered in this study.

We have faced some challenges in our study caused by COVID-19 pandemic announcement during our study in which the new regulations provided by our health authorities and conducted on WHO makes follow-up of elective cases is challenging.

\section{Conclusion}

Internal helmet technique used in correction of sagittal synostosis in children below 6 months old giving good cosmetic results with the following advantages, (1) short surgery time, (2) small wound, (3) no much blood loss, (4) immediate good cosmetic result, (5) no need to use external devices which reduces the cost, family load, and child suffering, and (6) no need for long-term follow-up.

\section{References}

1. David LR, Wilson JA, Watson NE, Argenta LC. Cerebra perfusion defects secondary to simple craniosynostosis. J Craniofac Surg. 1996;7(3):177-85. http://doi. org/10.1097/00001665-199605000-00003

PMid:9086882 
2. Hunter AG, Rudd NL. Craniosynostosis. I. Sagittal synostosis; its genetics and associated clinical findings in 214 patients who lacked involvement of the coronal suture(s). Teratology. 1976;14(2):185-93. http://doi. org/10.1002/tera.1420140209

\section{PMid:982314}

3. Lannelongue M. De la craniectomie dans la microcephalie. C R Seances Acad Sci. 1890;110:1382.

4. Shillito J, Matson DD. Craniosynostosis: A review of 519 surgical patients. Pediatrics. 1968;41(4):829-53.

PMid:5643989

5. Tamburrini G, Caldarelli M, Massimi L, Santini P, Di Rocco C Intracranial pressure monitoring in children with single suture and complex craniosynostosis: A review. Childs Nerv Syst. 2005;21(10):913-21. http://doi.org/10.1007/ s00381-004-1117-x

PMid:15871027

Author Queries???

AQ1: Kindly cite part figure 3 in text part. 